\title{
Synchrovax SEM Plasmid DNA Vaccine
}

National Cancer Institute

\section{Source}

National Cancer Institute. Synchrovax SEM Plasmid DNA Vaccine. NCI Thesaurus. Code C28549.

A bivalent DNA vaccine encoding epitopes for both Melan-A (MART -1) and tyrosinase with potential antineoplastic activity. Synchrovax SEM plasmid DNA vaccine contains a plasmid pSEM that encodes 4 epitopes: Melan-A (26-35), Melan-A (31-96), tyrosinase (19), and tyrosinase (369-377). Both Melan-A and tyrosinase are tumor antigens associated with melanoma. Vaccination with this plasmid DNA vaccine may induce both humoral and cytotoxic lymphocyte (CTL) responses against cells expressing either or both of these antigens, resulting in decreased tumor growth. 